\title{
Association between intimate partner violence and child morbidity in South Asia

\author{
Elma Z. Ferdousy ${ }^{*}$ and Mohammad A. Matin
}

\begin{abstract}
Background: This study investigates the association between intimate partner violence (IPV) against women and its impact on child morbidity in the south Asian region.

Methods: The analysis uses logistic regression models with cross sectional nationally representative data from three countries - Bangladesh, India and Nepal. The data have been pooled from 'Demographic and Health Surveys' (DHS) of Bangladesh, Nepal and 'National Family and Health Survey' (NFHS) of India.

Results: The study revealed that after controlling for potential confounders, children of mothers experiencing physical violence, sexual violence or both were more likely to have Acute Respiratory Infection (ARI) (ORadj 1.57; $95 \%$ $\mathrm{Cl} 1.48-1.67)$, fever ( $\left.\mathrm{OR}_{\mathrm{adj}} 1.44 ; 95 \% \mathrm{Cl} 1.35-1.54\right)$ and diarrhea (ORadj 1.56; $95 \% \mathrm{Cl}$ 1.44-1.69).

Conclusions: The results highlight that IPV can influence childhood morbidity and support the need to address IPV with a greater focus within current child nutrition and health programs and policies.
\end{abstract}

Keywords: Intimate partner violence, Childhood morbidity, South Asian Region, Bangladesh DHS, India DHS, Nepal DHS

\section{Background}

During the last decade several studies investigated the impact of intimate partner violence (IPV) on children's health. A recent study by World Health Organization (WHO) shows that the global prevalence of physical and/or sexual intimate partner violence among all ever-partnered women was $30.0 \%$ [39]. The estimates of physical and sexual violence are substantially higher in the developing countries in general $[12,14,25]$. South Asia reports some of the highest rates of violence [17, 20,30].

Evidence is available on negative consequences of IPV for women's health and well-being [6]. Several studies reported the link between IPV and women's mental health and depression $[8,28]$. Some of the studies also highlighted an association between such violence and reproductive health outcomes like non-use of contraception, gynecological problems, unintended pregnancy and sexually transmitted infections including HIV/AIDS. These results suggest there may be direct or indirect impact of IPV on children as well.

Significant attention has also been dedicated to the potential negative role of IPV on the health and survival of

\footnotetext{
* Correspondence: elma@juniv.edu

Department of Statistics, Jahangirnagar University, Savar, Dhaka
}

infants. Some population based studies have reported considerable adverse effects of IPV upon gestational and birth outcomes [3]. This also contributes in part to the association between IPV and prematurity or low birth weight $[31,38]$.

Studies on the association between IPV and childhood mortality are much more limited. Most of such studies come from developed countries. Scanty literature on this topic in the developing world includes some studies from India and one study from Bangladesh. Several studies from north India suggested significant association between lifetime IPV and infant mortality risks $[1,2,19,23]$. A population-based study from rural Bangladesh convincingly showed association between IPV and child mortality [5].

Studies in Bangladesh convincingly showed that children of women exposed to IPV have greater exposure to potentially dangerous conditions like diarrhea and Acute Respiratory Infection (ARI) [4, 36]. Impact of IPV on child nutrition has also been demonstrated by a few studies $[3,40]$.

The current study builds upon the existing literature and explores association between IPV and childhood morbidity expanding the study beyond a single country to include three neighboring countries in South Asia, i.e., Bangladesh, India and Nepal. 


\section{Methods}

\section{Study population and sampling procedure}

The study uses three datasets [16]- Bangladesh Demographic and Health Survey (DHS) 2007, India National Family and Health Survey (NFHS) - 2005-06 and Nepal DHS 2011. Both DHS and NFHS are nationallyrepresentative household surveys on population, health, and nutrition. These surveys employed a two stage sampling procedure with the first stage involving the selection of primary sampling units (PSUs); these were probability proportional to the size and represent the number of households within the PSU. The second stage used a systematic technique to sample households from each of the selected PSUs. The details of the methods and procedures used in data collection in DHS and NFHS surveys are provided in the respective DHS and NFHS reports [18, 27, 29]. Informed consent was obtained from the study participants. All these three surveys have similar modules on violence. These questions were administered to a sub-sample.

This secondary analysis includes a total of 40,394 women from India, Bangladesh and Nepal. The women selected for the violence module had at least one child under the age of 5 years during the survey. We included all the children under the age of 5 years in this sample. Therefore a total number of 58,725 children of these women were included in the study.

\section{Ethical clearance and considerations}

The original survey was administrated in accordance with the WHO ethical and safety guidelines for research on IPV. The institution review board of ICF Macro (formerly Macro International Inc.), an advisory, implementation, and evaluation services firm providing research-based solutions to U.S. federal government agencies in health and other areas. Reviewed and approved the surveys used in the study. The interviewers received special training to implement this module. The training focused on how to ask sensitive questions, ensure privacy, and build rapport between interviewer and respondent. Verbal Informed consent was also obtained from the respondents. Details of the informed consent statement can be found in the appendix section of the respective reports $[18,27,29]$.

\section{Exposure and outcome measures}

This study considers IPV as the main exposure variable while child morbidity as the outcome of interest.

\section{IPV}

Women were asked the following questions about their experience of IPV involving their husbands over the past 12 months. i. Has your husband pushed, shook or threw something?

ii. Has your husband slapped you?

iii. Has your husband twisted your arm or pulled your hair?

iv. Has your husband punched with fist or something harmful?

v. Has your husband kicked you, dragged you or beaten you up?

vi. Have you been threatened by a weapon or had a weapon used against you by your husband? Has your husband been choked you or burn you on purpose?

vii. Have you been physically forced to have sex or otherwise sexually abused by your husband?

A new dummy IPV variable was created based on the answer to the above questions. A positive response to any one of the first six questions was treated as indicative of physical IPV victimization and was coded as " 1 " and if none of the responses was positive, exposure to physical violence was coded as "0". A similar strategy was followed for deriving a variable indicating exposure or non-exposure to sexual IPV. Then two more variables were created to indicate exposure to any IPV or both IPV.

\section{Child morbidity}

Women were asked whether their child had been ill with fever, diarrhea, or a cough accompanied by short, rapid breathing in the 2 weeks prior to the surveys. Acute Respiratory Infection (ARI) was defined as the presence of cough, along with short, rapid breathing. Binary variables for Diarrhea, ARI and Fever were created which indicated the presence of each of these outcomes among the children in the past 2 weeks prior the survey. For these cases, " 0 " indicated absence of the symptoms while " 1 " indicated presence of the same.

\section{Covariates}

The study controlled for well established correlates of child morbidity such as age, religion, education, living standard, employment status and areas of residence [18, 27, 29].

Respondent's age was classified into 5 groups. The respondents were asked if they attended any educational institution and if yes then the highest level completed (primary, secondary, higher) was asked. We used the information to classify education of the mother into the following categories: (no education, primary, secondary \& higher).

Respondents were asked about the main source of drinking water for their household and presented with options like piped water, tube well or borehole, dug well, spring water, surface water etc. The responses were 
Table 1 Background characteristics of women and their children included in the study (pooled data)

\begin{tabular}{|c|c|c|c|}
\hline Variables & $\begin{array}{l}\text { Percent of Women } \\
(n=40,394)\end{array}$ & Variables & $\begin{array}{l}\text { Percent of } \\
\text { Children } \\
(n=58,725)\end{array}$ \\
\hline Age Groups & & Mother's Age & \\
\hline $15-19$ & 9.5 & $15-19$ & 5.2 \\
\hline $20-24$ & 24.8 & $20-24$ & 32.3 \\
\hline $25-29$ & 30.4 & $25-29$ & 34.6 \\
\hline $30-39$ & 28.6 & $30-39$ & 25.4 \\
\hline $40-49$ & 6.8 & $40-49$ & 2.5 \\
\hline Education Level & & Mother's Education & \\
\hline No Education & 38.6 & No Education & 40.8 \\
\hline Primary & 37.5 & Primary & 37.1 \\
\hline Secondary & 15.6 & Secondary & 14.5 \\
\hline Higher & 8.3 & Higher & 7.6 \\
\hline Type of residence & & Type of residence & \\
\hline Urban & 39.6 & Urban & 37.8 \\
\hline Rural & 60.4 & Rural & 62.2 \\
\hline Wealth Index & & Wealth Index & \\
\hline Poorest & 17.5 & Poorest & 17.8 \\
\hline Poorer & 17.8 & Poorer & 18.6 \\
\hline Middle & 19.8 & Middle & 20.7 \\
\hline Richer & 21.7 & Richer & 21.9 \\
\hline Richest & 23.3 & Richest & 21.0 \\
\hline $\begin{array}{l}\text { Source of } \\
\text { Drinking Water }\end{array}$ & & $\begin{array}{l}\text { Source of } \\
\text { Drinking Water }\end{array}$ & \\
\hline $\begin{array}{l}\text { Tube well or } \\
\text { Borehole }\end{array}$ & 32.1 & $\begin{array}{l}\text { Tube well or } \\
\text { Borehole }\end{array}$ & 36.6 \\
\hline Piped Connection & 41.1 & Piped Connection & 38.8 \\
\hline Other & 26.8 & Other & 24.6 \\
\hline Toilet Facility & & Toilet Facility & \\
\hline No Facility & 41.6 & No Facility & 30.8 \\
\hline Flush & 28.2 & Flush & 26.5 \\
\hline Pit latrine or other & 30.2 & Pit latrine or other & 42.7 \\
\hline Exposed to IPV & & Morbidity & \\
\hline Physical violence & 30.4 & Fever & 15.4 \\
\hline Sexual violence & 8.8 & Diarrhea & 9.8 \\
\hline Both/Either & 32.6 & ARI & 8.9 \\
\hline
\end{tabular}

grouped into three major categories: Tube well or borehole, piped water and other sources. Women were asked about the toilet facility and the responses were classified in the groups of pit latrine, flush and no facility. Cooking fuel of the household was classified into: electricity, gas, kerosene, wood/coal and others.

We used the DHS wealth index calculated as follows: each asset was assigned a weight (factor score) generated through principal component analysis, and the resulting asset scores were standardized in relation to a normal
Table 2 Different forms of violence and child morbidity

\begin{tabular}{|c|c|c|c|c|c|c|}
\hline & \multicolumn{2}{|l|}{ Fever } & \multicolumn{2}{|c|}{$\underline{\text { Diarrhea }}$} & \multicolumn{2}{|l|}{ ARI } \\
\hline & No & Yes & No & Yes & No & Yes \\
\hline \multicolumn{7}{|c|}{ Sexual Only } \\
\hline No & $85.7 \%$ & $14.3 \%$ & $91.7 \%$ & $8.3 \%$ & $86.8 \%$ & $13.2 \%$ \\
\hline Yes & $77.4 \%$ & $22.6 \%$ & $85.1 \%$ & $14.9 \%$ & $82.0 \%$ & $18.0 \%$ \\
\hline$p$ value & $<0.001$ & & $<0.001$ & & $<0.001$ & \\
\hline \multicolumn{7}{|c|}{ Physical Only } \\
\hline No & $86.9 \%$ & $13.1 \%$ & $92.4 \%$ & $7.6 \%$ & $90.9 \%$ & $9.1 \%$ \\
\hline Yes & $80.6 \%$ & $19.4 \%$ & $88.3 \%$ & $11.7 \%$ & $76.1 \%$ & $23.9 \%$ \\
\hline$p$ value & $<0.001$ & & $<0.001$ & & $<0.001$ & \\
\hline \multicolumn{7}{|l|}{ Both } \\
\hline No & $85.6 \%$ & $14.4 \%$ & $91.6 \%$ & $8.4 \%$ & $88.2 \%$ & $11.8 \%$ \\
\hline Yes & $76.5 \%$ & $23.5 \%$ & $84.4 \%$ & $15.6 \%$ & $60.7 \%$ & $39.3 \%$ \\
\hline$p$ value & $<0.001$ & & $<0.001$ & & $<0.001$ & \\
\hline
\end{tabular}

distribution with a mean of zero and standard deviation of one. Each household was then assigned a score for each asset, and the scores were summed for each household; individuals were ranked according to the total score of the household in which they resided. The sample was then divided into quintiles from one (lowest) to five (highest).

\section{Statistical analysis}

We calculated descriptive statistics for socio-demographic and morbidity characteristics for our selected sample individuals. The relationhip between morbidity and selected demographic and socio-economic factors were examined first using chi-square test. Then we used logistic regression models for exploring the relationship between IPV and different child morbidity outcomes. After this step we ran multiple logistic regression analysis. We calculated the

Table 3 Adjusted odds ratios and $95 \%$ confidence intervals for associations between different forms of maternal IPV and under-five child morbidity (pooled data)*

\begin{tabular}{|c|c|c|c|}
\hline & Fever & Diarrhea & ARI \\
\hline \multicolumn{4}{|c|}{ Physical IPV only } \\
\hline No & 1.00 & 1.00 & 1.00 \\
\hline Yes & $1.46(1.37,1.55)$ & $1.55(1.46,1.64)$ & $1.53(1.42,1.64)$ \\
\hline \multicolumn{4}{|c|}{ Sexual IPV only } \\
\hline No & 1.00 & 1.00 & 1.00 \\
\hline Yes & $1.67(1.59,1.75)$ & $1.79(1.62,1.98)$ & $1.72(1.59,1.87)$ \\
\hline \multicolumn{4}{|c|}{ Both physical and sexual IPV } \\
\hline No & 1.00 & 1.00 & 1.00 \\
\hline Yes & $1.64(1.49,1.81)$ & $1.66(1.49,1.81)$ & $1.76(1.61,1.92)$ \\
\hline \multicolumn{4}{|c|}{ Physical or sexual IPV } \\
\hline No & 1.00 & 1.00 & 1.00 \\
\hline Yes & $1.44(1.35,1.54)$ & $1.56(1.44,1.69)$ & $1.57(1.48,1.67)$ \\
\hline
\end{tabular}

*Adjusted for maternal age, maternal education, type of residence, types of cooking fuel, wealth index, toilet facility, and source of drinking water 
Table 4 Adjusted and unadjusted odds ratios and $95 \%$ confidence intervals any IPV and covariates

\begin{tabular}{|c|c|c|c|c|c|c|c|c|c|c|c|c|}
\hline \multirow[b]{3}{*}{ Variables } & \multicolumn{4}{|l|}{ Fever } & \multicolumn{4}{|c|}{ Diarrhea } & \multicolumn{4}{|l|}{ ARI } \\
\hline & \multicolumn{2}{|c|}{ Unadjusted } & \multicolumn{2}{|c|}{ Adjusted } & \multicolumn{2}{|c|}{ Unadjusted } & \multicolumn{2}{|c|}{ Adjusted } & \multicolumn{2}{|c|}{ Unadjusted } & \multicolumn{2}{|c|}{ Adjusted } \\
\hline & OR & $\mathrm{Cl}$ & OR & $\mathrm{Cl}$ & OR & $\mathrm{Cl}$ & OR & $\mathrm{Cl}$ & OR & $\mathrm{Cl}$ & OR & $\mathrm{Cl}$ \\
\hline \multicolumn{13}{|l|}{ Any IPV } \\
\hline No (Reference) & 1 & & 1 & & 1 & & 1 & & 1 & & 1 & \\
\hline \multirow[t]{2}{*}{ Yes } & 1.61 & 1.51 & 1.44 & 1.35 & 1.75 & 1.62 & 1.56 & 1.44 & 1.74 & 1.64 & 1.57 & 1.48 \\
\hline & & 1.71 & & 1.54 & & 1.88 & & 1.69 & & 1.84 & & 1.67 \\
\hline \multicolumn{13}{|l|}{ Mother's Age } \\
\hline 15-19 (Reference) & 1 & & 1 & & 1 & & 1 & & 1 & & 1 & \\
\hline \multirow[t]{2}{*}{$20-24$} & 1.95 & 1.74 & 1.94 & 1.73 & 1.88 & 1.65 & 1.82 & 1.58 & 1.93 & 1.73 & 1.9 & 1.71 \\
\hline & & 2.19 & & 2.18 & & 2.19 & & 2.11 & & 2.14 & & 2.12 \\
\hline \multirow[t]{2}{*}{$25-29$} & 1.71 & 1.53 & 1.76 & 1.57 & 1.55 & 1.35 & 1.52 & 1.32 & 1.64 & 1.48 & 1.68 & 1.51 \\
\hline & & 1.91 & & 1.98 & & 1.78 & & 1.76 & & 1.83 & & 1.88 \\
\hline \multirow[t]{2}{*}{ 30-39 } & 1.43 & 1.26 & 1.48 & 1.31 & 1.27 & 1.09 & 1.27 & 1.09 & 1.27 & 1.13 & 1.31 & 1.17 \\
\hline & & 1.61 & & 1.67 & & 1.47 & & 1.48 & & 1.41 & & 1.47 \\
\hline \multirow[t]{2}{*}{$40-49$} & 1.14 & 0.98 & 1.15 & 0.99 & 0.90 & 0.78 & 0.89 & 0.73 & 0.97 & 0.85 & 0.99 & 0.86 \\
\hline & & 1.31 & & 1.33 & & 1.09 & & 1.07 & & 1.12 & & 1.14 \\
\hline \multicolumn{13}{|l|}{ Mother's highest education level } \\
\hline No Education (Reference) & 1 & & 1 & & 1 & & 1 & & 1 & & 1 & \\
\hline \multirow[t]{2}{*}{ Primary } & 1.14 & 1.06 & 1.08 & 1.00 & 0.95 & 0.86 & 0.93 & 0.84 & 1.22 & 1.13 & 1.12 & 1.04 \\
\hline & & 1.24 & & 1.18 & & 1.05 & & 1.03 & & 1.31 & & 1.20 \\
\hline \multirow[t]{2}{*}{ Secondary } & 0.98 & 0.92 & 1.04 & 0.97 & 0.92 & 0.85 & 0.99 & 0.90 & 1.05 & 0.99 & 1.09 & 0.96 \\
\hline & & 1.05 & & 1.12 & & 1.00 & & 1.08 & & 1.12 & & 1.24 \\
\hline Higher & 0.77 & 0.69 & 0.98 & 0.85 & 0.60 & 0.51 & 0.78 & 0.65 & 0.82 & 0.74 & 0.95 & 0.88 \\
\hline & & 0.86 & & 1.12 & & 0.69 & & 0.94 & & 0.91 & & 1.02 \\
\hline Type of Residence & & & & & & & & & & & & \\
\hline Urban (Reference) & 1 & & 1 & & 1 & & 1 & & 1 & & 1 & \\
\hline Rural & 1.15 & 1.09 & 1.03 & 0.95 & 1.12 & 1.04 & 1.06 & 0.93 & 1.10 & 1.04 & 1.16 & 1.07 \\
\hline & & 1.22 & & 1.14 & & 1.20 & & 1.18 & & 1.16 & & 1.25 \\
\hline Wealth Index & & & & & & & & & & & & \\
\hline Poorest (Reference) & 1 & & 1 & & 1 & & 1 & & 1 & & 1 & \\
\hline Poorer & 1.05 & 0.96 & 0.99 & 0.91 & 0.95 & 0.85 & 0.95 & 0.85 & 1.05 & 0.97 & 0.99 & 0.91 \\
\hline & & 1.14 & & 1.09 & & 1.06 & & 1.07 & & 1.14 & & 1.08 \\
\hline Middle & 0.91 & 0.84 & 0.88 & 0.80 & 0.94 & 0.85 & 0.96 & 0.86 & 0.98 & 0.90 & 0.92 & 0.83 \\
\hline & & 1.00 & & 0.97 & & 1.05 & & 1.08 & & 1.06 & & 1.00 \\
\hline Richer & 0.87 & 0.80 & 0.91 & 0.81 & 0.84 & 0.75 & 0.89 & 0.77 & 0.90 & 0.83 & 0.86 & 0.77 \\
\hline & & 0.95 & & 1.02 & & 0.93 & & 1.02 & & 0.98 & & 0.96 \\
\hline Richest & 0.70 & 0.64 & 0.86 & 0.75 & 0.62 & 0.56 & 0.74 & 0.62 & 0.71 & 0.66 & 0.78 & 0.68 \\
\hline & & 0.76 & & 1.00 & & 0.70 & & 0.89 & & 0.77 & & 0.89 \\
\hline Source of Drinking water & & & & & & & & & & & & \\
\hline Tube well/ Borehole (Reference) & 1 & & 1 & & 1 & & 1 & & 1 & & 1 & \\
\hline Piped Water & 0.98 & 0.92 & 0.80 & 0.68 & 0.78 & 0.72 & 0.98 & 0.90 & 1.03 & 0.96 & 0.91 & 0.77 \\
\hline & & 1.05 & & 0.94 & & 0.85 & & 1.07 & & 1.10 & & 1.07 \\
\hline Other & 1.51 & 1.41 & 1.45 & 1.34 & 1.49 & 1.39 & 1.32 & 0.70 & 1.05 & 0.96 & 1.43 & 1.33 \\
\hline & & 1.62 & & 1.56 & & 1.58 & & 2.47 & & 1.14 & & 1.53 \\
\hline
\end{tabular}


Table 4 Adjusted and unadjusted odds ratios and $95 \%$ confidence intervals any IPV and covariates (Continued)

\begin{tabular}{|c|c|c|c|c|c|c|c|c|c|c|c|c|}
\hline \multicolumn{13}{|l|}{ Type of Toilet Facility } \\
\hline Pit Latrine (Reference) & 1 & & 1 & & 1 & & 1 & & 1 & & 1 & \\
\hline \multirow[t]{2}{*}{ Flush } & 0.95 & 0.90 & 0.95 & 0.74 & 0.79 & 0.73 & 0.83 & 0.68 & 0.97 & 0.92 & 0.91 & 0.57 \\
\hline & & 1.01 & & 1.20 & & 0.85 & & 1.02 & & 1.03 & & 1.44 \\
\hline \multirow[t]{2}{*}{ No facility } & 1.56 & 1.45 & 1.79 & 1.50 & 1.69 & 1.56 & 1.63 & 1.19 & 1.03 & 0.93 & 0.94 & 0.74 \\
\hline & & 1.69 & & 2.13 & & 1.80 & & 2.24 & & 1.15 & & 1.19 \\
\hline \multicolumn{13}{|l|}{ Type of Cooking fuel } \\
\hline Electricity (Reference) & 1 & & 1 & & 1 & & 1 & & 1 & & 1 & \\
\hline \multirow[t]{2}{*}{ Gas } & 1.33 & 1.00 & 0.80 & 0.60 & 1.29 & 0.70 & 1.05 & 0.95 & 1.32 & 0.84 & 0.86 & 0.65 \\
\hline & & 1.77 & & 1.08 & & 2.40 & & 1.17 & & 2.07 & & 1.13 \\
\hline \multirow[t]{2}{*}{ Kerosene } & 1.39 & 1.09 & 1.27 & 0.99 & 1.36 & 1.01 & 1.10 & 0.88 & 1.31 & 1.05 & 1.19 & 0.95 \\
\hline & & 1.76 & & 1.62 & & 1.83 & & 1.37 & & 1.63 & & 1.49 \\
\hline \multirow[t]{2}{*}{ Wood/Coal } & 1.73 & 1.1 & 1.14 & 0.71 & 1.45 & 1.02 & 1.26 & 0.87 & 1.43 & 1.10 & 1.6 & 1.47 \\
\hline & & 2.74 & & 1.81 & & 2.06 & & 1.82 & & 1.85 & & 1.73 \\
\hline \multirow[t]{2}{*}{ Other } & 1.96 & 1.55 & 1.75 & 1.61 & 1.78 & 1.32 & 1.61 & 1.19 & 1.78 & 1.44 & 1.58 & 1.34 \\
\hline & & 2.48 & & 1.90 & & 2.38 & & 2.18 & & 2.21 & & 1.89 \\
\hline
\end{tabular}

adjusted odds ratio to measure the strength of associations. SPSS version 17 was used for the analysis.

\section{Results}

Background characteristics of the women and their children are presented in Table 1. Most of the women were aged between 20 and 30 years and around $40 \%$ of them had no formal education. Approximately one third of these women reported experience of IPV.

In Table 2, presents the results of cross tabulation between different form of violence against women and the three diseases of interest. Across board a higher proportion of the children of abused mothers experienced the illnesses. Mothers exposed to sexual violence reported more incidents of child fever, diarrhea or ARI which are 22.6, 14.9 and $18.0 \%$ respectively compared to children of sexually non- abused mothers $14.3,8.3$ and $13.2 \%$ respectively $(p<0.001)$.

Table 3 shows the results of multivariate logistic regression analysis controlled for mothers' age, education, and wealth index, type of residence, source of drinking water, toilet facility and type of cooking fuel as covariates. Table 4 shows adjusted and unadjusted result for each of the controlling variables.

The results show that Maternal experience of physical IPV increased the likelihood of child fever by $46 \%$ (AOR: 1.46, $95 \% \mathrm{CI}: 1.37-1.55$ ), sexual IPV by $67 \%$ (AOR: 1.67, $95 \%$ CI: 1.59-1.87), and both physical and sexual IPV by $64 \%$ (AOR: 1.64, 95 \% CI: 1.49-1.81).

Maternal exposure to physical IPV increased the risks of diarrhea of the child by $55 \%$ (AOR: 1.55, $95 \% \mathrm{CI}$ : 1.46-1.64), sexual IPV by $79 \%$ (AOR: 1.79, $95 \% \mathrm{CI}$ :
1.62-1.98) and both physical and sexual IPV by $66 \%$ (AOR: 1.66, 95 \% CI: 1.49-1.81).

Maternal experience of physical IPV increased the likelihood of child's ARI by 53 \% (AOR: 1.53, $95 \% \mathrm{CI}$ : 1.42-1.64) sexual IPV by $72 \%$ (AOR: 1.72, $95 \% \mathrm{CI}$ : $1.59-1.87)$ and both physical and sexual IPV by $76 \%$ (AOR: 1.76, 95 \% CI: 1.61-1.92).

\section{Discussion}

The central aim of this study was to investigate the association between Intimate Partner Violence against women and child morbidity in South. The results of the study provide evidence of an association between IPV and child morbidity in these three countries of South Asia. The results are in line with previous findings $[1,2,5,15,19,21$, $23,33,35,36]$. We found that a higher proportion of the children of IPV survivors reported fever, diarrhea or ARI compared to the non abused mothers irrespective of the form of violence. There may be several approaches to explain the association between IPV and child morbidity. We offer the following three classes among them:

- Poor mental health of the mother: Women who experience IPV tend to have higher level of psychological stress $[10,26]$ which may impede their capacity to provide adequate child care. There are physiological reasons for psychological stress is associated to anemia. Psychological stress is a risk factor for oxidative stress $[9,13]$, that produce free radicals and other organic molecules capable of damaging living tissue and can destroy red blood cells prematurely that results in a potential cause of hemolytic anemia. Additionally chronic stress has 
been found to result in long term reduction of hemoglobin suggesting that stress interferes with protein synthesis required to create new red blood cells. Conditions like anemia can weaken a person and lowers a person's productivity through a decreased ability to work [37]. These physical conditions contribute poor child caring ability of a woman.

- Lack of empowerment: Intimate partner violence is often used as a tool for controlling women [32]. Thus IPV is also strongly associated with inability of a woman to make decision for herself and for her children [34] with obvious implications for her own health and nutrition and that of her children. Lack of empowerment also limits mother's ability to access household resources, health care services and participation in common health care activities [32, 34] which in turn lowers their ability to provide appropriate care to their children.

- Poor physical condition of the mother: In case of extreme IPV often the victims become physically unfit to give proper care to their children.

Besides, the children who witness IPV themselves tend to experience psychological stress; which in turn result in poor physiological conditions making the children vulnerable to morbidity [7, 11, 22]. Investigation of the specific pathways through which IPV might influence child health and morbidity should be a high priority for future research.

\section{Limitation}

The cross sectional study design represents a limitation of this study. Though there may be some concern regarding the temporal ordering of IPV and child morbidity in cross sectional studies, previous research shows that IPV in this subcontinent is a relatively stable phenomenon that has its root in patriarchal structures and community norms of high acceptability of wife beating [24].

Another limitation of the study is that both the outcome and the exposure variables are measured through self reports. Although in the DHS much care and preparation is taken into the design and execution of the interviews to create a safe atmosphere in which respondents would feel comfortable discussing the IPV, high stake in disclosure may always cause under reporting.

\section{Conclusion}

The study shows that IPV negatively affects child's health not only in individual countries, but also in the South Asia region. The children of an abused mother are more likely to experience diseases like fever, diarrhea and ARI compared to the children of non-abused mothers. IPV should be considered as a major health problem affecting not only women, but also their children in South Asia. Although it seems IPV is most strongly associated with socioeconomic demographic and contextual disadvantages, incidents of IPV among socially marginalized groups may aggravate the negative effects of cumulative disadvantages of poor child health outcomes. The health sector in these countries needs to take action to eliminate IPV for improving child health. Future studies should investigate the influence of potential mechanisms mediating the association of IPV and child morbidity.

\section{Competing interests}

The authors declare that they have no competing interests.

\section{Authors' contributions}

EZF analyzed and interpreted the data and wrote the initial draft of the manuscript. MAM provided guidance in data analyses and interpretation of results. Both authors read and approved the final version of the manuscript.

\section{Acknowledgement}

The authors are grateful to DHS Program and ICF International of Calverton for providing the datasets.

Received: 15 June 2015 Accepted: 26 June 2015

Published online: 14 August 2015

\section{References}

1. Ackerson SL, Subramanian SV. Intimate partner violence and death among infants and children in India. Pediatrics. 2009;124:878-89.

2. Ahmed S, Koenig MA, Stephenson RB. Effect of domestic violence on early childhood mortality: evidence from North India. Am J Pub Health. 2006;96:1423-8.

3. Asling-Monemi K, Naved RT, Persson LA. Violence against women and the risk of fetal and early childhood growth impairment: a cohort study in rural Bangladesh. Arch Dis Child. 2009:94:775-9.

4. Asling-Monemi K, Naved RT, Persson LA. Violence against women and increases in the risk of diarrheal disease and respiratory tract infections in infancy: a prospective cohort study in Bangladesh. Arch Pediatr Adolesc Med. 2009:163(10):931-6.

5. Asling-Monemi K, Tabassum NR, Persson LA. Violence against women and the risk of under five mortality: analysis of community-based data from rural Bangladesh. Acta Paediatr. 2008:97:226-32

6. Campbell JC. Health consequences of intimate partner violence. Lancet. 2002:359:1331-6.

7. Campbell JC, Lewandowski LA. Mental and physical health effects of intimate partner violence on women and children. Psychiatr Clin North Am. 1997;20:353-74.

8. Ellsberg M, Caldera T, Herrera A, Winkvist A, Kullgren G. Domestic violence and emotional distress among Nicaraguan women: results from a population-based study. Am Psychologist. 1999;54:30-6.

9. Epel ES, Blackburn EH, Lin J, Dhabhar FS, Adler NE, Morrow JD, et al. Accelerated telomere shortening in response to life stress. Proc Natl Acad Sci U S A. 2004;101:17312-5.

10. Fikree FF, Bhatti LI. Domestic violence and health of Pakistani women. Int J Gynaecol Obstet. 1999:65:195-201.

11. Finkelstein J, Yates JK. Traumatic symptomatology in children who witness marital violence. Int J Emerg Ment Health. 2001;3:107-14.

12. Garcia-Moreno C, Jansen HAFM, Ellsberg M, Heise L, Watts CH. Prevalence of intimate partner violence: findings from the WHO multi-country study on women's health and domestic violence. Lancet. 2006:368:1260-9.

13. Hapuarachchi JR, Chalmers AH, Winefield AH, Blake-Mortimer JS. Changes in clinically relevant metabolites with psychological stress parameters. Behav Med. 2003;29:52-9.

14. Heise L, Pitanguy J, Germain A. Violence against women: The hidden health burden. World Bank Discussion Paper 1994; no. WDP 255.

15. Holt S, Buckley $\mathrm{H}$, Whelan S. The impact of exposure to domestic violence on children and young people. Child Abuse Negl. 2008;32:797-810.

16. ICF International, USAID. Demographic and Health Surveys (various) [Datasets] Available from <http://dhsprogram.com/data/available-datasets.cfm> [July, 2012] 
17. International Institute for Population Sciences (IIPS) and Macro International. National Family Health Survey (NFHS-3), 2005-06. India: Volume I. Mumbai: IIPS; 2007.

18. International Institute for Population Sciences (IIPS) and Macro International. National Family Health Survey (NFHS-3), 2005-06. India: Volume I and II. Mumbai: IIPS; 2007.

19. Jejeebhoy SJ. Associations between wife-beating and fetal and infant death: impressions from a survey in rural India. Stud Fam Plann. 1998:29:300-8.

20. Jejeebhoy SJ, Cook RJ. State accountability for wife-beating: the Indian challenge. Lancet. 1997;349:SI10-2.

21. Jejeebhoy SJ, Santhya KG, Acharya R. Health and social consequences of marital violence: a synthesis of evidence from India. New Delhi: Population Council and UNFPA; 2010.

22. Kitzmann KM, Gaylord NK, Holt AR, Kenny ED. Child witnesses to domestic violence: a meta-analytic review. J Consult Clin Psychol. 2003;71:339-52.

23. Koenig MA, Stephenson R, Acharya R, Barrick L, Ahmed S, Hindin M. Domestic violence and early childhood mortality in rural India: evidence from prospective data, Int. J. Epidemiol. 2010;39:825-83.

24. Koenig MA, Stephenson R, Ahmed S, Jejeebhoy SJ, Campbell J. Individual and contextual determinants of domestic violence in North India. Am J Public Health. 2006;96(1):132-8.

25. Krug EG, Mercy JA, Dahlberg LL, Zwi AB. The world report on violence and health. Lancet. 2002;360:1083-8

26. Kumar S, Jeyaseelan L, Suresh S, Ahuja RC. Domestic violence and its menta health correlates in Indian women. Br J Psychiatry. 2005;187:62-7.

27. Ministry of Health and Population (MOHP) [Nepal], New ERA, and ICF International Inc. Nepal demographic and health survey 2011. Kathmandu, Nepal: Ministry of Health and Population, New ERA, and ICF International, Calverton, Maryland; 2012.

28. Mullen PE, Romans-Clarkson SE, Walton VA, Herbison GP. Impact of sexual and physical abuse on women's mental health. Lancet. 1988;8590:841-5.

29. National Institute of Population Research and Training (NIPORT), Mitra and Associates, and Macro International. Bangladesh demographic and health survey 2007. Dhaka, Bangladesh and Calverton, Maryland, USA: National Institute of Population Research and Training, Mitra and Associates, and Macro International; 2009.

30. Naved RT, Persson LA. Factors associated with spousal physical violence against women in Bangladesh. Stud Fam Plann. 2005;36:289-300.

31. Newberger EH, Barkan SE, Lieberman ES, McCormick MC, Yllo K, Gary LT. Abuse of pregnant women and adverse birth outcome: current knowledge and implications for practice. JAMA. 1992;267:2370-2

32. Pence E, McDonnell C. Duluth, MN, Power and control wheel. Domestic Abuse Intervention Project 1984.

33. Rico E, Fenn B, Abramsky T, Watts C. Associations between maternal experiences of intimate partner violence and child nutrition and mortality: findings from Demographic and Health surveys in Egypt, Honduras, Kenya, Malawi and Rwanda. J Epidemiol Comm Health. 2011;65:360-7.

34. Sethuraman K, Lansdown R, Sullivan K. Women's empowerment and domestic violence: the role of sociocultural determinants in maternal and child undernutrition in tribal and rural communities in South India. Food Nutr Bull. 2006;27:128-43.

35. Silverman JG, Decker MR, Cheng DM, Wirth K, Saggurti N, RAj A, et al. Gender-based disparities in infant and child mortality based on maternal exposure to spousal violence: the heavy burden borne by Indian girls. Arch Pediatr Adolesc Med. 2011:165:22-7.

36. Silverman JG, Decker MR, Gupta J, Kapur N, Raj A, Naved RT. Maternal experiences of intimate partner violence and child morbidity in bangladesh: evidence from a national Bangladeshi sample. Arch Pediatr Adolesc Med. 2009:163(8):700-5.

37. Smith Jr RE. The clinical and economic burden of anemia. Am J Manag Care. 2010;16(supp):S59-66.

38. Valladares E, Ellsberg M, Pena R, Hogberg U, Persson LA. Physical partner abuse during pregnancy: a risk factor for low birth weight in Nicaragua. Obstet Gynecol. 2002;100:700-5.

39. World Health Organization. Global and regional estimates of violence against women: prevalence and health effects of intimate partner violence and non-partner sexual violence. Switzerland: World Health Organ; 2013.

40. Ziaei S, Naved RT, Ekström EC. Women's exposure to intimate partner violence and child malnutrition: findings from demographic and health surveys in Bangladesh. Matern Child Nutr. 2014;10(3):347-59.

\section{Submit your next manuscript to BioMed Central and take full advantage of:}

- Convenient online submission

- Thorough peer review

- No space constraints or color figure charges

- Immediate publication on acceptance

- Inclusion in PubMed, CAS, Scopus and Google Scholar

- Research which is freely available for redistribution

Submit your manuscript at www.biomedcentral.com/submit 